\title{
Numerical investigations of reactive pollutant dispersion and personal exposure in 3D urban-like models
}

Article

Accepted Version

Creative Commons: Attribution-Noncommercial-No Derivative Works 4.0

Zhang, Y., Yang, X., Yang, H., Zhang, K., Wang, X., Hang, J., Luo, Z. and Zhou, S. (2020) Numerical investigations of reactive pollutant dispersion and personal exposure in 3D urban-like models. Building and Environment, 169. 106569. ISSN 0360-1323 doi:

https://doi.org/10.1016/j.buildenv.2019.106569 Available at https://centaur.reading.ac.uk/87490/

It is advisable to refer to the publisher's version if you intend to cite from the work. See Guidance on citing.

To link to this article DOI: http://dx.doi.org/10.1016/j.buildenv.2019.106569

Publisher: Elsevier

All outputs in CentAUR are protected by Intellectual Property Rights law, including copyright law. Copyright and IPR is retained by the creators or other copyright holders. Terms and conditions for use of this material are defined in the End User Agreement. 


\section{CentAUR}

Central Archive at the University of Reading

Reading's research outputs online 
1 To be submitted to Building and Environment 2019

2

3 Numerical investigations of reactive pollutant

4 dispersion and personal exposure in 3D urban-like models

6 Yong Zhang ${ }^{1}$, Xia Yang ${ }^{1}$, Hongyu Yang ${ }^{1}$, Keer Zhang ${ }^{1}$, Xuemei Wang ${ }^{2}$, Zhiwen

$7 \quad$ Luo $^{3}$, Jian Hang ${ }^{1,4 *}$, Shengzhen Zhou ${ }^{1 *}$

8

$9 \quad{ }^{1}$ School of Atmospheric Sciences, Guangdong Province Key Laboratory for Climate

10 Change and Natural Disaster Studies, Sun Yat-sen University, Guangzhou, P.R. China

112 Institute for Environmental and Climate Research, Jinan University, Guangzhou, P. R.

12 China

$13{ }^{3}$ School of the Built Environment, University of Reading, UK

$14{ }^{4}$ National Supercomputer center in Guangzhou, P.R. China

$16 *$ Corresponding author: Jian Hang, Shengzhen Zhou

17 Tel: +86-13710248541; +86-13710952752

E-mail address: hangj3@mail.sysu.edu.cn; zhoushzh3@mail.sysu.edu.cn 
With satisfactory validation by experimental data, we perform computational fluid dynamic(CFD) simulations with the standard $k-\varepsilon$ model to investigate how NO- $\mathrm{NO}_{2}-\mathrm{O}_{3}$ photochemistry and turbulent mixing influence reactive pollutant dispersion and vehicular $\mathrm{NO}_{\mathrm{x}}$ exposure in 21-row(neighborhood-scale 1km) three-dimensional(3D) medium-dense urban models with an approaching wind parallel(perpendicular) to the main(secondary) streets. Personal intake fraction $P_{-} i F$ and its spatially-averaged values for the entire building (i.e. building intake fraction $\left.\left\langle P \_i F\right\rangle_{\mathrm{B}}\right)$ are adopted for reactive/passive exposure analysis with/without $\mathrm{NO}_{x}-\mathrm{O}_{3}$-photochemistry.

Some meaningful findings are proposed: 1) There are flow adjustment processes coupling turbulent mixing and chemical reactions through urban areas(i.e. secondary Street 1 to 20). $\mathrm{NO}-\mathrm{NO}_{2}-\mathrm{O}_{3}$ photochemistry induces $\mathrm{O}_{3}$ depletion and $\mathrm{NO}$ conversion into $\mathrm{NO}_{2}$ producing significant increase in $\mathrm{NO}_{2}$ exposure and slight decrease in $\mathrm{NO}$ exposure compared with passive dispersion. 2) With span-wise $\mathrm{NO}_{\mathrm{x}}$ sources, Street 10 in the fully-developed region experiences weaker wind and subsequently greater $\left\langle P \_i F\right\rangle_{\mathrm{B}}(0.207 \mathrm{ppm})$ than $\operatorname{Street} 3(0.135 \mathrm{ppm})$ in the upstream flow-adjustment region. $\left\langle P \_i F\right\rangle_{\mathrm{B}}$ descends exponentially from the target building toward downstream, and Street 10 experiences quicker decay rates. 3) With stream-wise $\mathrm{NO}_{\mathrm{x}}$ sources along the main street, $\left\langle P \_i F\right\rangle_{\mathrm{B}}$ first ascends, then reaches equilibrium values (e.g.0.046-0.049ppm for passive). 4) If background $\mathrm{O}_{3}$ concentration $\left[\mathrm{O}_{3}\right]$ rises from $20 \mathrm{ppbv}$ to 40 and $100 \mathrm{ppbv}$, more $\mathrm{NO}$ is oxidized by $\mathrm{O}_{3}$ to generate $\mathrm{NO}_{2}$. As $\left[\mathrm{O}_{3}\right]=20 \mathrm{ppbv}$, if $\mathrm{NO}-\mathrm{NO}_{2}$ emission ratio decreases from 10 to $5, \mathrm{NO}_{2}$ exposure is 
partly offset but NO exposure change little. Present methodologies are confirmed effective to investigate impacts of more complicated meteorological conditions and chemical mechanisms on exposure in urban districts.

Keywords: $\mathrm{NO}_{-} \mathrm{NO}_{2}-\mathrm{O}_{3}$ photochemistry; reactive pollutant dispersion; personal intake fraction $\left(P_{-} i F\right)$; building intake fraction $\left(\left\langle P \_i F\right\rangle_{\mathrm{B}}\right)$; computational fluid dynamic (CFD) simulation; three-dimensional (3D) urban models

\section{Introduction}

Following the ongoing urbanization worldwide, vehicular pollutant emissions have become one of the major sources in urban air pollution[1-3]. Heavy traffic flows, compact urban configurations and unfavorable meteorological conditions are the main reasons of large pollutant exposure and adverse health impacts on city dwellers[4]. On average, people spend more than $90 \%$ of their time indoors. Outdoor air pollutants in urban areas can penetrate into indoor via doors, windows, building cracks and other ventilation duct systems[5-7]. Particularly, vehicular pollutant exposure to urban residents living near busy roads should be paid more attention, because they suffer from higher health risks than other urban microenvironments[7-10]. Apart from reducing vehicular pollutant emissions, sustainable urban design with better understanding the influence of urban layouts and atmospheric conditions on the flow and passive/reactive pollutant dispersion in urban areas can help enhancing pollutant 
dilution and mitigating traffic-related pollutant exposure[11-15].

As reviewed by the literature[16-29], in the past decades, a number of computational fluid dynamic (CFD) simulations, outdoor field observations and wind tunnel experiments have been widely performed to clarify turbulent flow characteristics and pollutant dispersion in urban models from street-scale $(\sim 100 \mathrm{~m})$ to neighborhood-scale $(\sim 1 \mathrm{~km})$. Street aspect ratios $(H / W)$ are reported as the most key urban parameters in two-dimensional (2D) street canyons[16-18, 25-26, 29-32]. Realistic urban districts are usually three-dimensional (3D) with pollutant exchange across street roofs and lateral/stream-wise urban boundaries. Generally, the building planar area index $\lambda_{p}$ (i.e. the ratio between the planar area of buildings viewed from above and the total floor area) and the frontal area index $\lambda_{f}$ (i.e. the ratio of the frontal area of buildings to the total floor area) are typical building packing density indexes and key parameters of 3D urban areas[33-38]. Moreover, other significant factors have been also verified, such as building height variations[38-40], ambient wind directions[40-41], elevated building design[42-44], tree planting[46-49] etc. In addition, thermal stratification and buoyancy forces induced by wall heating and solar shading also significantly influence or dominate the flow and pollutant dispersion if wind speed is relatively small and Richardson number is large[50-56].

Recently, several researches[7, 44, 57] introduce personal intake fraction $\left(P_{-} i F\right)$ to quantify street-scale pollutant exposure induced by vehicle emissions. In contrast to population intake fraction $(I F)$ for a specific population $[4,58], P_{-} i F$ is independent of population density and size which represents the fraction of pollutants inhaled 
averagely by each person of a population to the total pollutant emissions. For example, $1 \mathrm{ppm}$ (part per million or $10^{-6}$ ) means the inhalation of $1 \mathrm{mg}$ pollutants if $1 \mathrm{~kg}$ pollutants being emitted. By performing CFD simulations validated by experimental data, Hang et al.[7] estimated spatial mean $P \_i F$ (i.e. $\left\langle P \_i F>\sim 1-5 \mathrm{ppm}\right.$ ) of passive pollutant (i.e. $\mathrm{CO})$ in shallow $2 \mathrm{D}$ street canyons $(H / W=0.5-1)$. Later, $\left\langle P \_i F\right\rangle$ in 3D urban district models were confirmed one order smaller $(\sim 0.1 \mathrm{ppm})$ than $2 \mathrm{D}$ models with similar aspect ratios $(H / W=0.5-1)[41,57]$.

Besides the dynamic dispersion of passive pollutants, there are chemical processes of reactive pollutants in urban streets, such as the $\mathrm{NO}_{\mathrm{x}}-\mathrm{O}_{3}$ photochemistry [59-64], $\mathrm{NO}_{\mathrm{x}}-\mathrm{O}_{3}-$ VOCs chemical mechanisms[65-69] etc. Among them, the impacts of different heating scenarios and building configurations on reactive dispersion are extensively investigated through LES or RANS approaches, such as various shading settings[61], wall heating scenarios[60, 62], aspect ratios[63] etc. However, most studies so far mainly examine reactive pollutant dispersion in 2D street canyons while investigations on reactive pollutant dispersion and the related exposure in $3 \mathrm{D}$ urban models are still rare. Therefore, this study incorporates $\mathrm{NO}-\mathrm{NO}_{2}-\mathrm{O}_{3}$ chemistry into CFD simulations and numerically investigates reactive pollutant dispersion and exposure in urban models. As a start, the impacts of various ground-level source locations and reactant proportions $\left(\mathrm{NO}: \mathrm{NO}_{2}: \mathrm{O}_{3}\right)$ in $3 \mathrm{D}$ medium-dense urban models $\left(H / W=1, \lambda_{p}=\lambda_{f}=0.25\right)$ are studied under neutral meteorological conditions.

The sketch of this paper is organized as follows: Section 2 introduces the indexes for pollutant dispersion and exposure. Section 3 illustrates model setups and all test 
108

cases in CFD simulations. Section 4 presents the flow and pollutant dispersion validations by wind tunnel data. Section 5 shows results and discussions, and Section 6 draws the conclusions.

\section{Indexes for pollutant dispersion and exposure}

\subsection{Personal intake fraction $\left(P_{-} i F\right)$ and building intake fraction $\left(\left\langle P_{-} i F\right\rangle_{B}\right)$}

Population intake fraction $(I F)$ and personal intake fraction $\left(P \_i F\right)$ are effective indexes to quantify vehicular pollutant exposure in local streets or neighborhoods[41, 44, 57]. Both exposure indexes are defined as Eq. (1):

$$
\begin{gathered}
I F=\sum_{i}^{\mathrm{N}} \sum_{j}^{M} P_{i} \times B r_{i, j} \times \Delta t_{i, j} \times C e_{j} \dot{m} \\
P_{-} i F=I F / \sum_{j}^{M} P_{i}
\end{gathered}
$$

where, $N$ and $M$ are the number of age groups and microenvironments, $P_{i}$ represents the population size for the age group $i, B r_{i, j}\left(\mathrm{~m}^{3} / \mathrm{s}\right)$ and $\Delta t_{i, j}(\mathrm{~s})$ are the average breathing rate and the individual time spent for the $i$ th age group in the $j$ th microenvironment, $C e_{j}\left(\mathrm{~kg} / \mathrm{m}^{3}\right)$ denotes pollutant concentration in microenvironment $j$ and $\dot{m}(\mathrm{~kg})$ means total emissions released from vehicles. It is worth mentioning that $P \_i F$ is independent of pollutant release rates as well as population density and size, but can be influenced by building configurations, meteorological conditions and pollutant source settings etc. 
three $\operatorname{subgroups}(N=3$, Fig. 1a): Children(21.2\%), Adults(63.3\%) and Elders(15.5\%).

Moreover, the time activity patterns for each subgroup are divided into four microenvironments $(M=4$, Fig. $1 b)$ : indoors at home $(j=1)$, other indoor locations $(j=2)$, in or near vehicles $(j=3)$, and other outdoor locations $(j=4)$. Table 1 lists activity time patterns and breathing rates in each subgroup for indoors at home $(j=1)$. In this study, all present building models are supposed to residential type and only $j=1$ (indoors at home) is adopted to calculate $P \_i F[44,57]$. Especially, the area-averaged $P \_i F$ of the building wall surface is denoted as wall intake fraction $\left(\left\langle P \_i F\right\rangle_{\mathrm{W}}\right)$. The spatially-averaged $P \_i F$ of the entire building surfaces is represented as building intake fraction $\left(\left\langle P \_i F\right\rangle_{\mathrm{B}}\right)$, which means the fraction of total traffic emissions inhaled averagely by each person living in this roadside building.

\subsection{Photostationary state defect $\left(d_{p s}\right.$, unit: \%)}

Referring to previous researches[59-60], the photostationary state defect $\left(d_{p s}\right)$ is an effective indicator to measure the departure degree from photochemical equilibrium and can be expressed in the following form:

$$
d_{p s}=\left(\frac{k_{I}[\mathrm{NO}]\left[\mathrm{O}_{3}\right]}{J_{\mathrm{NO}_{2}}\left[\mathrm{NO}_{2}\right]}-1\right) \times 100
$$

here, $k_{1}[\mathrm{NO}]\left[\mathrm{O}_{3}\right]$ and $J_{\mathrm{NO}_{2}}\left[\mathrm{NO}_{2}\right]$ represent the depletion and generation rates of ozone. $d_{p s}$ is positive value if ozone depletion rate greater than its formation rate, and vice versa. Especially, $d_{p s}$ equals zero when chemical reactions reach equilibrium state. 


\section{CFD setups and case descriptions}

151

152

153

154

155

156

157

158

159

160

161

162

163

164

165

166

167

\subsection{Numerical approaches}

With advances in computer technologies, CFD as a powerful modelling tool has been widely employed to reproduce turbulent flow structure as well as to predict pollutant dispersion and transport in urban districts. Though large eddy simulations (LES) have been confirmed to be more accurate in predicting turbulence than Reynolds-Averaged Navier-Stokes (RANS) models[27, 73-75], RANS approaches are still extensively used, since LES models require expensive computational expenses and have challenges in selecting sub-grid scale models and specifying appropriate boundary conditions. Moreover, among the RANS models (e.g. various $k-\varepsilon$ and $k-\omega$ models), the standard $k-\varepsilon$ model shows good agreements with experimental data and has been widely adopted[7-8, 37-38, 45, 57-58, 76-79], although it has limitations in predicting turbulent kinetic energy in strong-wind regions. Therefore, by considering model performance and computational loads, the standard $k-\varepsilon$ model is selected to solve the steady-state isothermal flow field. The governing equations for the flow and turbulent quantities implemented are as below[80]:

The mass continuity equation:

$$
\frac{\partial \bar{u}_{j}}{\partial x_{j}}=0
$$

The momentum equation: 


$$
\bar{u}_{j} \frac{\partial \bar{u}_{i}}{\partial x_{j}}=-\frac{1}{\rho} \frac{\partial \bar{p}}{\partial x_{i}}+\frac{\partial}{\partial x_{j}}\left(v \frac{\partial \bar{u}_{i}}{\partial x_{j}} \overline{-u_{i}^{\prime} u_{j}^{\prime}}\right)
$$

170

173 where, $\bar{u}_{j}$ is mean velocity components $\left(\bar{u}_{j}=\bar{u}, \bar{v}, \bar{w}\right.$ as $\left.j=1,2,3\right) ; v$ and $v_{t}=C_{\mu} \frac{k^{2}}{\varepsilon}$ 174

The transport equations of turbulent kinetic energy $(k)$ and its dissipation rate $(\varepsilon)$ :

$$
\begin{gathered}
\bar{u}_{i} \frac{\partial k}{\partial x_{i}}=\frac{\partial}{\partial x_{i}}\left[\left(v+\frac{v_{t}}{\sigma_{k}}\right) \frac{\partial k}{\partial x_{i}}\right]+P_{k^{-}} \\
\bar{u}_{i} \frac{\partial \varepsilon}{\partial x_{i}}=\frac{\partial}{\partial x_{i}}\left[\left(v+\frac{v_{t}}{\sigma_{\varepsilon}}\right) \frac{\partial \varepsilon}{\partial x_{i}}\right]+C_{\varepsilon 1} \frac{\varepsilon}{k} P_{k^{-}} C_{\varepsilon 2} \frac{\varepsilon^{2}}{k}
\end{gathered}
$$

$\left(C_{\mu}=0.09\right)$ represent the kinematic viscosity and the eddy viscosity, respectively; the

Reynolds stress tensor $-\overline{u_{i}{ }^{\prime} u_{j}^{\prime}}$ and the turbulence production term $P_{k}$ are defined as:

$$
\begin{aligned}
& -\overline{u_{i}^{\prime} u_{j}^{\prime}}=v_{t}\left(\frac{\partial \bar{u}_{i}}{\partial x_{j}}+\frac{\partial \bar{u}_{j}}{\partial x_{i}}\right)-\frac{2}{3} k \delta_{i j} \\
& P_{k}=v_{t} \times \frac{\partial \bar{u}_{i}}{\partial x_{j}}\left(\frac{\partial \bar{u}_{i}}{\partial x_{j}}+\frac{\partial \bar{u}_{j}}{\partial x_{i}}\right)
\end{aligned}
$$

Note that $\delta_{i j}$ is the Kronecker delta whose value is 1 when $i=j$ and otherwise is 0 .

The $\mathrm{NO}_{\mathrm{x}}-\mathrm{O}_{3}$ simple photochemical mechanism is described as follows[59-60]:

$$
\mathrm{NO}_{2}+h v \rightarrow \mathrm{NO}+\mathrm{O}, \quad J_{\mathrm{NO}_{2}}
$$

$$
\mathrm{O}+\mathrm{O}_{2}+M \rightarrow \mathrm{O}_{3}+M, \quad k_{2}
$$

$$
\mathrm{O}_{3}+\mathrm{NO} \rightarrow \mathrm{NO}_{2}+\mathrm{O}_{2}, \quad k_{1}
$$

Here, $M$ denotes a third molecule, for example $\mathrm{O}_{2}$ or $\mathrm{N}_{2}$, to absorb excess energy and stabilize $\mathrm{O}_{3}$ molecule formed; $J_{\mathrm{NO}_{2}}, k_{2}$ and $k_{1}$ represent rate constant for each reaction, respectively. Since the oxygen atom (O) is highly reactive, it combines rapidly with $\mathrm{O}_{2}$ once $\mathrm{O}$ is produced from $\mathrm{NO}_{2}$ photolysis. This is so-called pseudo-steady-state approximation that the depletion and production rates of $\mathrm{O}_{3}$ are 
nearly equal[81]:

$$
k_{2}[\mathrm{O}]\left[\mathrm{O}_{2}\right][\mathrm{M}]=J_{N O_{2}}\left[\mathrm{NO}_{2}\right]
$$

Therefore, Eq. (9a) is the rate control step for $\mathrm{O}_{3}$ formation. Based on the above assumption, the transport equations for reactive pollutants can be defined as[59-60]:

$$
\begin{aligned}
& \bar{u}_{j} \frac{\partial[\mathrm{NO}]}{\partial x_{j}}=D_{m} \frac{\partial^{2}[\mathrm{NO}]}{\partial x_{j} \partial x_{j}}+\frac{\partial}{\partial x_{j}}\left(D_{e} \frac{\partial[\mathrm{NO}]}{\partial x_{j}}\right)+J_{N O_{2}}\left[\mathrm{NO}_{2}\right]-k_{1}\left[\mathrm{O}_{3}\right][\mathrm{NO}]+S_{N O} \\
& \bar{u}_{j} \frac{\partial\left[\mathrm{NO}_{2}\right]}{\partial x_{j}}=D_{m} \frac{\partial^{2}\left[\mathrm{NO}_{2}\right]}{\partial x_{j} \partial x_{j}}+\frac{\partial}{\partial x_{j}}\left(D_{e} \frac{\partial\left[\mathrm{NO}_{2}\right]}{\left.\partial x_{j}\right]}\right)-J_{\mathrm{NO}_{2}}\left[\mathrm{NO}_{2}\right]+k_{1}\left[\mathrm{O}_{3}\right][\mathrm{NO}]+S_{\mathrm{NO}_{2}} \\
& \bar{u}_{j} \frac{\partial\left[\mathrm{O}_{3}\right]}{\partial x_{j}}=D_{m} \frac{\partial^{2}\left[O_{3}\right]}{\partial x_{j} \partial x_{j}}+\frac{\partial}{\partial x_{j}}\left(D_{e} \frac{\partial\left[\mathrm{O}_{3}\right]}{\partial x_{j}}\right)+J_{\mathrm{NO}_{2}}\left[\mathrm{NO}_{2}\right]-k_{1}\left[\mathrm{O}_{3}\right][\mathrm{NO}]
\end{aligned}
$$

where, $D_{m}$ and $D_{e}$ are the molecular and eddy diffusivity; the third terms on the right-hand side of Eq. (11) represent chemical reaction term; $S_{\mathrm{NO}}$ and $S_{\mathrm{NO}_{2}}$ denote the source terms of $\mathrm{NO}$ and $\mathrm{NO}_{2}$; the Schmidt number $S c_{t}=v_{t} / D_{e}$ is specified as $0.7[33,39$, $46,48,78]$. Furthermore, the photolysis rate $J_{\mathrm{NO}_{2}}$ and rate constant $k_{1}$ are calculated by [59-60]:

$J_{\mathrm{NO}_{2}}=8.14 \times 10^{-3}\left\{0.97694+8.3700 \times 10^{-4}(T-273.15)+4.5173 \times 10^{-6} \times(T-273.15)^{2}\right\}(12 \mathrm{a}$ )

$$
k_{1}=4.405 \times 10^{-2} \exp \left(-\frac{1370}{T}\right)
$$

Here, $T$ is temperature in $\mathrm{K}$; the units of $J_{\mathrm{NO}_{2}}$ and $k_{1}$ are $\mathrm{s}^{-1}$ and $\mathrm{ppbv}^{-1} \mathrm{~s}^{-1}$. Additionally, the temperature-dependent rate constant is not considered in isothermal flow of this study, thus $J_{\mathrm{NO}_{2}}$ and $k_{1}$ are $8.1 \times 10^{-3} \mathrm{~s}^{-1}$ and $4.450 \times 10^{-4} \mathrm{ppbv}^{-1} \mathrm{~s}^{-1}$ by assuming reactive pollutants undergo chemical processes under the isothermal condition with a fixed $T$ of $298.15 \mathrm{~K}$. 
All governing equations(Eqs. $(3-6,11))$ are discretized by a finite volume method (FVM) with the second-order upwind scheme. The SIMPLE algorithm is employed for pressure and velocity coupling. The under-relaxation factors for pressure, momentum, $k$ and $\varepsilon$ terms are specified as $0.3,0.7,0.8$ and 0.8 . Numerical simulation does not stop until the absolute residuals of all variables are less than $10^{-6}$.

\subsection{Three-dimensional (3D) urban model setups in CFD}

The building layouts, as depicted in Fig. 2a, are based on the idealized 3D medium-dense urban clusters (i.e. street aspect ratio $H / W=1$; building packing density $\lambda_{p}=\lambda_{f}=0.25$ ). To better illustrate model configurations, $x, y$ and $z$ are described as the stream-wise, span-wise and vertical directions, respectively. The cubic building $\operatorname{models}(H=B=30 \mathrm{~m})$ with a uniform $\operatorname{spacing}\left(W_{s}=W_{m}=30 \mathrm{~m}\right)$ are constructed in $x$ and $y$ directions. Moreover, the approaching wind is parallel to the main $\operatorname{streets}(x$ direction $)$ and perpendicular to the secondary streets( $y$ direction). $x / H=0$ means the cross section in windward street opening and $y / H=0$ denotes the central cross section of the main street (Fig. 2c).

As verified by the literature[38-40, 82-83], the airflow in the middle column is hardly affected by lateral boundaries if the lateral width of the urban model is sufficiently large. Hence, only half of the middle column with two lateral symmetry boundaries are considered during CFD simulations to reduce computational efforts (Fig. 2b). Following the CFD guidelines[84-86], the distances between urban 
boundaries and the domain top, domain inlet, domain outlet are $9 H, 6.7 H$ and $32.3 H$, respectively. Furthermore, the zero normal gradient boundary condition is adopted at two lateral boundaries and the domain top (i.e. symmetry) and the domain outlet (i.e. outflow). Several recent studies[5-6, 8-9, 44, 57-58] reported that, pollutant concentration on the wall surfaces of near-road buildings can be treated as indoor concentration originated from outdoor pollutants since the indoor/outdoor $(\mathrm{I} / \mathrm{O})$ ratio of pollutant concentration is nearly one for naturally-ventilated buildings[5, 72]. Therefore, by assuming all present building models are naturally-ventilated type, the flow and pollutant dispersion within indoor space of buildings are not taken into account to reduce the grid numbers and computational costs in CFD simulations. The literature have applied such technique to effectively quantify vehicular pollutant exposure in 2D street canyons or 3D urban models[5-6, 8-9, 44, 57-58].

For the domain inlet, the power-law time-averaged velocity profile $U_{0}(z)$ in the upstream free flow is adopted (Eq. 13a)[40-41, 57, 82-83] which is scaled to that in wind tunnel experiments[87]. Base on the CFD guideline[84-86], vertical profiles of $k(z)$ and $\varepsilon(z)$ are given by Eqs. (13b-c):

$$
U_{0}(z)=U_{r e f} \times(z / H)^{0.16}
$$

$$
k(z)=u_{*}^{2} / \sqrt{C_{\mu}}
$$

$$
\varepsilon(z)=C_{\mu}^{3 / 4} k^{3 / 2} /\left(\kappa_{v} z\right)
$$

where, $U_{\text {ref }}$ is the reference velocity at the building height in upstream free flow $\left(U_{\text {ref }}=3.0 \mathrm{~m} / \mathrm{s}\right.$ at $\left.z=H\right)$; the friction velocity $u *=0.24 \mathrm{~m} / \mathrm{s}[40-41,57,82-83]$; von 
250

251

252

253

254

255

256

257

Karman constant $\kappa_{v}=0.41, C_{\mu}=0.09$. Furthermore, vertical profiles of Eq. (13) represent neutral atmospheric boundary layer with a full-scale surface roughness $z_{0}=0.1 \mathrm{~m}[93]$ and have been adopted in previous studies[40-41, 57, 82-83].

In addition, Fig. $2 c$ demonstrates the overhead and lateral views of mesh distribution for test cases. The minimum grid size of $0.2 \mathrm{~m}$ near the wall surfaces and the stretching ratio between adjacent grids of 1.15 (about 3.2 million hexahedral cells) are applied to ensure sufficiently fine grid at the pedestrian level $(0-1.5 \mathrm{~m})$ and near building surfaces. As the normalized distance $y^{+}\left(y^{+}=y u_{\tau} / v\right)$ ranges from 30 to 600 at most regions of wall surfaces, standard wall function with no slip boundary condition is set on all wall surfaces. According to the literature[13, 40, 88-89], a specific roughness modification is assigned to the upstream and downstream ground to obtain a horizontally homogeneous ABL surrounding urban regions. Especially, the grid independence tests are presented later in subsection 4.1 .

\subsection{Pollutant source settings and model description of test cases}

Three kinds of pollutant source locations are considered in this study, i.e. the span-wise ( $y$ direction) emission sources in the $3^{\text {rd }}$ or $10^{\text {th }}$ secondary street is denoted as S3 and S10 (Fig. 3a-b), and the stream-wise ( $x$ direction) emission sources along the main street is represented by Sm (Fig. 3c). The reactive pollutants involved in present photochemistry are $\mathrm{NO}, \mathrm{NO}_{2}$ and $\mathrm{O}_{3}$. Among them, $\mathrm{NO}_{\mathrm{x}}$ is assumed to be emitted from vehicles into the street canyon while background $\mathrm{O}_{3}$ concentration is 
271

272

specified at the domain inlet and entrained by approaching wind into urban districts. The background concentrations for $\mathrm{NO}$ and $\mathrm{NO}_{2}$ at the domain inlet are zero in this study. Following the literature[59-60], typical automobile emission ratio of NO to $\mathrm{NO}_{2}\left(R_{\mathrm{NO} / \mathrm{NO}_{2}}\right)$ of 10 is adopted. $\mathrm{NO}$ and $\mathrm{NO}_{2}$ are released from the lowest grid cell $(z=0-0.2 \mathrm{~m})$ at rates of 100 and $10 \mathrm{ppbv} \mathrm{s}^{-1}$, which corresponds to emission strengths of $1.227 \times 10^{-7}$ and $1.88 \times 10^{-8} \mathrm{~kg} \mathrm{~m}^{-3} \mathrm{~s}^{-1}(P=1 \mathrm{~atm}, T=298.15 \mathrm{~K})$. For S3 or S10 sources, as the street width $\left(W_{s}\right)$ is $30 \mathrm{~m}$, this $\mathrm{NO}_{\mathrm{x}}$ emission intensity of $849 \mu \mathrm{g} \mathrm{m}^{-1} \mathrm{~s}^{-1}$ is equivalent to a traffic volume of about 6100 vehicles per hour when considering a $\mathrm{NO}_{\mathrm{x}}$ emission of $0.5 \mathrm{~g} \mathrm{~km}^{-1}$ per vehicle[59-60]. Particularly, we are mainly concerned with the proportion among $\mathrm{NO}$ and $\mathrm{NO}_{2}$ rather than the assigned emission rate for each vehicular pollutant.

Furthermore, four $\mathrm{O}_{3}$ background concentrations (i.e. $\left[\mathrm{O}_{3}\right]=1,20,40$ and 100 ppbv) with $R_{\mathrm{NO}_{\mathrm{NO}}}=100: 10$ are investigated to study the effects of different $\left[\mathrm{O}_{3}\right]$ on reactive dispersion. In addition, Carslaw[90] verified that there is an increasing $\mathrm{NO}_{2} / \mathrm{NO}_{\mathrm{x}}$ emission ratio in road traffic emissions referring to observation in real cities. Thus, three emission ratios of $\mathrm{NO}$ to $\mathrm{NO}_{2}$ (i.e. $R_{\mathrm{NO} / \mathrm{NO}_{2}}=100: 10,50: 10$ and 100:20) with $\left[\mathrm{O}_{3}\right]=20 \mathrm{ppbv}$ are considered to examine the impacts of various $R_{\mathrm{NO} / \mathrm{NO}_{2}}$ on reactive pollutant dispersion.

Overall, total 11 test cases are described as Case P [Source, $R_{\mathrm{NO} / \mathrm{NO}_{2}}$ ] or Case R [Source, $\left.R_{\mathrm{NO} / \mathrm{NO}_{2}},\left[\mathrm{O}_{3}\right]\right]$ and summarized in Table 2. Here 'P' means passive dispersion without chemical reactions, ' $\mathrm{R}$ ' denotes reactive dispersion with $\mathrm{NO}-\mathrm{NO}_{2}-\mathrm{O}_{3}$ chemistry; 'Source' contains three pollutant source locations, i.e. S3, S10 and Sm, 
293

294

295

296

297

298

299

300

301

302

303

304

305

306

307

308

309

310

311

312

313

respectively; $R_{\mathrm{NO} / \mathrm{NO}_{2}}$ represents the emission ratios of $\mathrm{NO}$ to $\mathrm{NO}_{2} ;\left[\mathrm{O}_{3}\right]$ is background $\mathrm{O}_{3}$ concentration (mole fraction, unit: ppbv).

\section{Validation study of flow and pollutant dispersion in 3D urban models}

\subsection{Flow validation by wind tunnel data}

In this subsection, the performances of various steady $k-\varepsilon$ models (standard, RNG and Realizable) with standard wall function are evaluated by wind tunnel data. Moreover, the grid independence tests are also implemented.

As shown in Fig. 4a-b, idealized 3D urban models in wind tunnel experiment[87] consist of 7 rows and 11 columns of regularly-aligned cubic buildings $(H=B=W=15 \mathrm{~cm})$. Vertical profiles of velocity components $(\bar{u}, \bar{w})$ and turbulence kinetic energy $(k)$ are measured at points of $\mathrm{V}_{i}(i=1-6)$, which are central positions in the $i$ th secondary street located at $y / H=1$ and $x / H=1.5 H, 3.5 H, 5.5 H, 7.5 H, 9.5 H$, 11.5H respectively (Fig. 4a-b).

In CFD validation study, the similar full-scale model configurations ( $H=B=W=30 \mathrm{~m}$, Fig. $4 \mathrm{c}$ ) are reconstructed with the scale ratio of $200: 1$ to wind-tunnel-scale models. Moreover, all CFD setups including computational domains, boundary conditions and convergence criteria in this full-scale CFD validation study are similar with those in subsection 3.2 except that the distance between urban boundaries and domain outlet is $40.3 H$ (Fig. 4c). Based on the building $\operatorname{height}(H=0.15 \mathrm{~m}$ or $30 \mathrm{~m})$ and reference velocity $\left(U_{\text {ref }}=3 \mathrm{~m} / \mathrm{s}\right)$, the reference Reynolds 
number $R e=\frac{U_{r e f} H}{v} \approx 30000$ and $6 \times 10^{6}$ for wind-tunnel-scale and full-scale urban models, which are much larger than 11000 satisfying Reynolds number independence requirement. Furthermore, Fig. 4d depicts the coarse, medium and fine grid arrangements with hexahedral cells of about 1,2 and 3.3 million and the minimum grid size of $0.4 \mathrm{~m}, 0.2 \mathrm{~m}$ and $0.1 \mathrm{~m}$, respectively.

Fig. 5 first shows results of grid independence test at V1(Fig. 5a-b), then depicts vertical profiles of time-averaged stream-wise velocity $\bar{u}(z)$ at Points V1, V4 and V6 (Fig. 5c-e), vertical velocity $\bar{w}(z)$ (Fig. 5f) and turbulence kinetic energy $k(z)$ (Fig. 5g) at Point V1 between numerical results and experimental data. There is little difference in numerical results between the coarse, medium and fine grid, and thus medium grid is selected for case studies to reduce computational loads. Besides, the standard $k-\varepsilon$ model with the medium grid shows better agreements with wind tunnel data than the RNG and Realizable $k-\varepsilon$ models.

To further quantify the modeling accuracy and reliability of the standard $k-\varepsilon$ model with the medium grid arrangement, several statistical performance metrics are applied, including the mean value, the standard deviation, the factor 2 (FAC2), the normalized mean square error (NMSE), the fraction bias (FB) and the correlation coefficient (R)[91]. Among which, the closer NMSE value to zero, the smaller difference between experiment data and CFD results; FAC2 value larger than one means over-prediction against experiment data while smaller than one represents under-prediction; Similarly, the negative and positive FB values denote overestimation and underestimation. Results of $\bar{u}(z)$ at Points V1, V4 and V6 as well 
as $\bar{w}(z)$ and $k(z)$ at Point V1 are listed in Table 3. Referring to COST Action 732's recommended criteria[91], a credible CFD model should satisfy the following statistical metrics standards: $0.5 \leqslant \mathrm{FAC} 2 \leqslant 2, \mathrm{NMSE} \leqslant 1.5$ and $-0.3 \leqslant \mathrm{FB} \leqslant 0.3$. Overall, metrics lie in the recommended criteria, particularly values of $\bar{u}(z)$ meet well. However, values of $\bar{w}(z)$ and $k(z)$ reveal relatively poorer performance than those of $\bar{u}(z)$, which is largely attributed to the limitation of the standard $k-\varepsilon$ model. Conclusively, the validation study shows that present CFD methodologies applying standard $k-\varepsilon$ model with medium grid have credible numerical accuracy in predicting urban turbulent flow and can be employed for further case studies.

\subsection{Validation of pollutant dispersion by wind tunnel data}

Experimental and numerical studies have been extensively performed to investigate passive pollutant dispersion in the idealized street canyons. Unfortunately, there are currently little experimental data to directly validate the present CFD model coupled with chemistry[59-60, 63-64]. However, the reactive pollutants considered in this paper are effectively passive and can be divided into two subsets, i.e. total nitrogen oxide $\left(\mathrm{NO}_{\mathrm{x}}=\mathrm{NO}+\mathrm{NO}_{2}\right)$ and total oxidant $\left(\mathrm{OX}=\mathrm{NO}_{2}+\mathrm{O}_{3}\right)$, since reactions $(\mathrm{Eq}$.

9) interconvert $\mathrm{NO}$ with $\mathrm{NO}_{2}$, and $\mathrm{O}_{3}$ with $\mathrm{NO}_{2}$ but without redundant productions. In addition, the chemical reaction terms cancel out when Eqs. (11a-b) and Eqs. (11b-c) are added, which indicates that the transport and dispersion of $\mathrm{NO}_{\mathrm{x}}$ and $\mathrm{OX}$ can be deemed as passive scalar. Consequently, in this subsection, Standard $k-\varepsilon$ model with 
standard wall function has been implemented and validated against wind tunnel experiment to evaluate the reliability of numerical simulation in predicting passive pollutant distribution.

The configurations of the wind tunnel measurement[92], as depicted in Fig.6a-b, are consisted of nine rectangular building models ( $L x=27.6 \mathrm{~cm}, L y=18.4 \mathrm{~cm}, H=8 \mathrm{~cm})$ with three rows and three columns $(3 \times 3)$ and uniform street widths $(W=8 \mathrm{~cm}, H / W=1)$. Moreover, tracer gas $\left(\mathrm{C}_{2} \mathrm{H}_{6}\right)$ is released from a line source $(0.5 \mathrm{~cm}$ in width, $d x$ and $18.4 \mathrm{~cm}$ in length, $L s$ ) at a velocity of $w_{\text {source }}=0.01 \mathrm{~m} / \mathrm{s}$ which is paralleled with $y$ direction and locates in the central street canyon in front of building No.2(Fig. 6a-b). Furthermore, $\mathrm{C}_{2} \mathrm{H}_{6}$ concentration profiles are measured in the middle of leeward and windward walls near the line source as well as on the central line of roof surface in the building No.2(Fig. 6a-b).

In full-scale pollutant dispersion validation study, similar model configurations ( $L x=138 \mathrm{~m}, L y=92 \mathrm{~m}, H=40 \mathrm{~m}$, in Fig. $6 \mathrm{c}$ ) are rebuilt with the scale ratio of 500:1 to wind-tunnel-scale models. CFD setups are similar with subsection 3.2, but the distances between urban boundaries and the domain top, domain side, domain inlet, domain outlet are $9 H, 5 H, 5 H$ and $15 H$, respectively. The approaching wind is parallel to the main streets( $x$ direction) and perpendicular to the secondary streets( $y$ direction). Furthermore, vertical profiles of stream-wise velocity $\bar{u}(z)$, turbulence kinetic energy $k(z)$ and turbulent dissipation rate $\varepsilon(z)$ fitted by measured data in wind tunnel experiments[92] are adopted at the domain inlet (Fig. 6d-f). In addition, to compare CFD results with measured data, the normalized $\mathrm{C}_{2} \mathrm{H}_{6}$ concentration $K$ is defined as 
below:

381

382

Here the height of building $(H)$, the reference velocity $\left(U_{r e f}\right)$ and the line source emission strength ( $\left.w_{\text {source }}, d x\right)$ are applied.

As shown in Fig. 7, the agreements of $K$ between wind tunnel data and CFD results are well confirming the standard $k-\varepsilon$ model has sufficient modeling accuracy in predicting passive pollutant dispersion within 3D urban district models.

\section{Results and discussion}

\subsection{Flow patterns in 3D urban district models}

Fig. 8 a depicts velocity distribution in the plane of $z=1.5 \mathrm{~m}$ (the pedestrian level). Obviously, the flow adjustment process can be observed through the entire building clusters, in which wind speed decreases toward downstream from Street 1 to Street 6, and then reaches a comparatively flow equilibrium from Street 7 to Street 18. Fig. $8 \mathrm{~b}-\mathrm{c}$ further depict velocity magnitude and $2 \mathrm{D}$ streamlines in the plane of $y=30 \mathrm{~m}$ (the center plane of the target street canyon) and $z=1.5 \mathrm{~m}$ for Street 3 and Street 10 . Moreover, the corresponding 3D streamlines are displayed in Fig. 8d. For both street units, 3D downward helical vortices are produced inside the secondary streets (Fig. 8b-d). The lateral flow direction near street ground (i.e. $z=1.5 \mathrm{~m}$ ) are from the secondary streets to the main streets and from the downwind building (No.4 and 11) 
to upwind building (No. 3 and 10) (Fig. 8c). In addition, Street 3 apparently experiences greater wind speed than Street 10. reactive pollutant dispersion in the fully-developed region (e.g. Street 10) than the flow-adjust region (e.g. Street 3).

\subsection{Impacts of source locations $(\mathrm{S3}, \mathrm{S10}$ and $\mathrm{Sm})$ on reactive pollutant dispersion}

This subsection considers the impacts of source locations (i.e. S3, S10 and Sm in

Fig. 3) on reactive pollutant dispersion(with chemical reactions, R-type) under the specific pollutant proportion (i.e. $R_{\mathrm{NO} / \mathrm{NO}_{2}}=100: 10,\left[\mathrm{O}_{3}\right]=20 \mathrm{ppbv}$ ). Because the present photochemical mechanism contains the interconversion of nitrogen oxides(i.e. $\mathrm{NO}_{\mathrm{x}}=\mathrm{NO}+\mathrm{NO}_{2}$ ) and oxidants (i.e. $\mathrm{OX}=\mathrm{NO}_{2}+\mathrm{O}_{3}$ ), The following discussions (subsection 5.2 and 5.3) concentrate more on $\mathrm{NO}_{2}$ to simplify analysis. Moreover, passive dispersion (without chemical reactions, P-type) are also presented to investigate the sole role of turbulent mixing.

\subsection{1 $\mathrm{NO}_{2}$ concentration distribution in 3D urban-like models}

Fig. 9a-d exhibit $\mathrm{NO}_{2}$ concentration between P-type(passive, left) and R-type (reactive, right) cases in $y=30 \mathrm{~m}$ and $z=1.5 \mathrm{~m}$ for Street 3 and 10 fixed with span-wise sources(i.e. S3 and S10). Moreover, Fig. 9e compares $\mathrm{NO}_{2}$ concentration at the 
pedestrian level between passive and reactive cases with $\mathrm{NO}_{\mathrm{x}}$ sources along main streets (i.e. Sm). For passive dispersion with S3 or S10 sources (P-type), due to source emissions and turbulent transports, $\mathrm{NO}_{2}$ concentration near the upwind building (No.3 and 10) is higher than that near the downwind building(Fig. 9a-b). Furthermore, a large amount of $\mathrm{NO}_{2}$ pollutants accumulate in the intersection of main street and secondary street(Fig. 9c-d). In an overall view, $\mathrm{NO}_{2}$ concentration in Street 10 is slightly higher than Street 3. For P-type case with $\mathrm{Sm}$ sources(Fig. 9e), $\mathrm{NO}_{2}$ concentration first rises toward downstream streets, then reaches an approximate equilibrium from Street 7 to 18 . Such findings are similar with the flow adjustment as discussed in subsection 5.1.

With chemical reactions, as verified by Fig. 9, $\mathrm{NO}_{2}$ concentration in R-type cases considerably exceeds that in P-type cases. Oppositely, passive NO concentration is higher than that in R-type cases.

\subsection{2 $d_{p s}$ distribution in Street 3 and 10}

Fig. 10 shows $d_{p s}$ distribution in $y=30 \mathrm{~m}$ and $z=1.5 \mathrm{~m}$ in local target streets with S3 and S10 sources. Here, the distribution of photostationary state $\operatorname{defect}\left(d_{p s}\right)$ is emphasized below the roof level $(z / H<1)$ and toward downstream domains (i.e. $x / H>5$ and $x / H>19$ for Street 3 and 10, respectively).

As introduced in subsection 2.2, smaller $d_{p s}$ value represents the less departure degree from photochemical equilibrium. In the centre plane of secondary streets 
( $y=30 \mathrm{~m}$, Fig. 10a), the local small $d_{p s}$ values emerge near the roof of the upwind

441 building (No.3 and 10) while the large $d_{p s}$ values appear near the roof of the 442 downwind building (No.4 and 11) and the ground level close to $\mathrm{NO}_{\mathrm{x}}$ emissions. At the 443 pedestrian level(Fig. 10b), downstream areas of the main streets $(x / H>6$ and $x / H>20)$ 444 experience small $d_{p s}$ values while the junction regions of the main street and 445 secondary street near $\mathrm{NO}_{\mathrm{x}}$ source locations obtain large $d_{p s}$ values, particularly in 446 Street 3. In summary, $d_{p s}$ value is usually smaller in regions with weaker wind and 447 turbulence, where reactive pollutants have more time to mix and react.

\subsubsection{Concentration, $\left\langle P_{-} i F\right\rangle_{\mathrm{W}}$ and $\left\langle P_{-} i F\right\rangle_{\mathrm{B}}$ on building wall surfaces}

Based on spatial mean concentration at the entire building surfaces, we calculate wall intake fraction $\left(\left\langle P_{\_} i F\right\rangle_{\mathrm{W}}\right)$ and building intake fraction $\left(\left\langle P_{-} i F\right\rangle_{\mathrm{B}}\right)$ to analyze overall vehicular pollutant $\left(\mathrm{NO}_{\mathrm{x}}\right)$ exposure in near-road buildings. Especially, 1ppm represents $1 \mathrm{mg}$ inhaled averagely by each person living in the near-road building if $1 \mathrm{~kg}$ pollutants emitted out.

Fig. 11a-b first compare $\mathrm{NO}_{2}$ concentration on the leeward and windward walls between P-type and R-type cases in target street units with S3 and S10 sources. No matter with or without chemical reactions, $\mathrm{NO}_{2}$ concentrations on the leeward wall 458 are always higher than those on the windward wall. Once $\mathrm{NO}_{\mathrm{x}}-\mathrm{O}_{3}$ photochemical reactions are conducted, an increase of $\mathrm{NO}_{2}$ concentration emerges on the upwind and downwind walls. Such results are similar with the aforementioned discussion in 
subsection 5.2.1.

Then, Table 4 lists $\left\langle P \_i F\right\rangle_{\mathrm{W}}$ of $\mathrm{NO}$ and $\mathrm{NO}_{2}$ at leeward and windward walls adjoining target street in cases with S3 and S10 (positions as described in Fig. 3a-b). Obviously, in both P-type and R-type cases, $\left\langle P \_i F\right\rangle_{\mathrm{W}}$ of $\mathrm{NO}_{\mathrm{x}}$ at leeward wall(Table 4, row 1-4, column 2-3) are greater than those at windward wall(Table 4, row1-4, column 4-5). Regarding P-type cases as the references, $\left\langle P \_i F\right\rangle_{\mathrm{W}}$ of $\mathrm{NO}_{2}$ in R-type cases rise nearly $90 \%-160 \%$, i.e. 0.660 to $1.372 \mathrm{ppm}$ and 0.853 to $1.643 \mathrm{ppm}$ at leeward wall for S3 and S10(Table 4, column 2), 0.180 to $0.473 \mathrm{ppm}$ and 0.230 to $0.610 \mathrm{ppm}$ at windward wall for S3 and S10(Table 4, column 4); while $\left\langle P \_i F\right\rangle_{\mathrm{W}}$ of NO reduces about $9 \%-16 \%$, i.e. 0.660 to $0.588 \mathrm{ppm}$ and 0.853 to $0.775 \mathrm{ppm}$ at leeward wall for S3 and S10(Table 4, column 3), 0.180 to $0.151 \mathrm{ppm}$ and 0.230 to $0.193 \mathrm{ppm}$ at windward wall for S3 and S10(Table 4, column 5). Because $\mathrm{NO}_{\mathrm{x}}$ emission ratio released from vehicles is $R_{\mathrm{NO} / \mathrm{NO}_{2}}=10$, the present photochemical processes lead to a significant increase in $\mathrm{NO}_{2}$ exposure and a slight decrease in $\mathrm{NO}$ exposure.

Furthermore, $\mathrm{NO}_{2}$ concentrations on the entire building wall surfaces with $\mathrm{Sm}$ sources are presented in Fig. 11c. Both P-type and R-type cases experience the $\mathrm{NO}_{2}$ concentration adjustment processes toward downstream buildings. To quantify $\mathrm{NO}_{\mathrm{x}}$ exposure adjustments in P-type and R-type cases with various sources (S3, S10 and $\mathrm{Sm})$, the horizontal profiles of building intake fraction $\left\langle P_{-} i F\right\rangle_{\mathrm{B}}$ of $\mathrm{NO}$ and $\mathrm{NO}_{2}$ are shown in Fig. 12. It is found that $\left\langle P \_i F\right\rangle_{\mathrm{B}}$ with S3 or S10 sources descends exponentially toward downstream buildings(Fig. 12a-b), instead, $\left\langle P_{-} i F\right\rangle_{\text {B }}$ with Sm sources first ascends quickly from building No.1 to 8, then reaches an approximate 
483

484

485

486

487

488

489

490

491

492

493

494

495

496

497

498

499

500

501

502

503

504

equilibrium(Fig. 12c). Besides, R-type cases experience larger $\mathrm{NO}_{2}$ exposure than P-type cases, i.e. $0.420-0.108 \mathrm{ppm}$ against $0.135-0.020 \mathrm{ppm}$ for S3(Fig. 12a), 0.605-0.160ppm against 0.207-0.030ppm for S10(Fig. 12b), 0.005-0.090ppm against 0.002-0.049ppm for Sm(Fig. 12c). Oppositely, NO exposure in P-type cases are greater than R-type cases, i.e. 0.135-0.020ppm than 0.106-0.010ppm for S3(Fig. 12a), 0.207-0.030ppm than $0.168-0.017 \mathrm{ppm}$ for S10(Fig. 12b) and 0.002-0.049ppm than 0.002-0.045ppm for Sm(Fig. 12c).

In addition, the decay function expressed in $\left\langle P_{-} i F_{n}\right\rangle_{\mathrm{B}}=a \times\left\langle P{ }_{-} i F_{t}\right\rangle_{\mathrm{B}} \times e^{(t-n) / b}$ is employed to further quantify the $\left\langle P \_i F\right\rangle_{\text {B }}$ decay processes from target building unit $(t$ $=4$ or 11) toward downstream building ( $n=t$ to 21$)$ in S3 and S10 cases. Note that, smaller decay factor $b$ means relatively sharper descending processes of $\left\langle P \_i F\right\rangle_{\mathrm{B}}$ curves. Table 5 summarizes the $\left\langle P_{-} i F_{t}\right\rangle_{\mathrm{B}}$ of building "No.t" and the exponential decay factors $b$ in S3 and S10 cases. Obviously, compared with those in P-type case ( $b=7.46$ and 3.96 in Table 5, row 1 and 3), R-type cases with S3 and S10 obtain larger $b$ for $\mathrm{NO}_{2}$ (10.80 and 6.84 in Table 5, row 2 and 4) and smaller $b$ for NO (5.92 and 2.91). Moreover, $\left\langle P \_i F\right\rangle_{\mathrm{B}}$ curves in $\mathrm{S} 10$ cases(Table 5, row 3-4) decline more sharply toward downstream regions than S3 cases(Table 5, row 1-2). Particularly, as shown in Fig. 12c, $\left\langle P_{-} i F_{t}\right\rangle_{\mathrm{B}}$ in Sm cases are calculated by the mean $\left\langle P \_i F\right\rangle_{\mathrm{B}}$ from building No.9 to 21, i.e. $0.048 \mathrm{ppm}$ in P-type case, $0.044 \mathrm{ppm}$ and $0.088 \mathrm{ppm}$ in R-type case for $\mathrm{NO}$ and $\mathrm{NO}_{2}$.

In summary, with $R_{\mathrm{NO} \mathrm{NO}_{2}}=100: 10$ and $\left[\mathrm{O}_{3}\right]=20 \mathrm{ppbv}$, the present $\mathrm{NO}_{\mathrm{x}}-\mathrm{O}_{3}$ titration interactions result in the production of $\mathrm{NO}_{2}$ and depletion of $\mathrm{O}_{3}$ and $\mathrm{NO}$. By 
505

506

507

508

509

510

511

512

513

514

515

516

517

518

519

520

521

522

523

524

focusing on $\left\langle P \_i F_{t}\right\rangle_{\mathrm{B}}$ values, $\mathrm{NO}_{2}$ exposure in R-type cases are greater than P-type cases about 3.1 times for $\mathrm{S} 3,2.9$ times for $\mathrm{S} 10$ and 1.8 times for $\mathrm{Sm}$ while NO exposure in R-type cases are nearly 21\%, $19 \%$ and $8 \%$ smaller than P-type cases for S3, S10 and Sm, respectively.

\subsection{Impacts of reactant proportions $\left(\mathrm{NO}: \mathrm{NO}_{2}: \mathrm{O}_{3}\right)$ on reactive pollutant dispersion}

In this subsection, based on S10 sources, we discuss the effects of different reactant proportions $\left(\mathrm{NO}: \mathrm{NO}_{2}: \mathrm{O}_{3}\right)$ on the interaction of turbulent mixing and photochemical processes in urban districts. Additionally, $P_{-} i F$ and $\left\langle P_{-} i F\right\rangle$ are independent on source emission strength in passive pollutant dispersion, therefore Case $\mathrm{P}[\mathrm{S} 10,100: 10]$ is treated as the reference case to compare with the cases with other reactant proportions.

\subsubsection{Impacts of $\mathrm{O}_{3}$ background concentration $\left(\left[\mathrm{O}_{3}\right]\right)$}

With the same emission ratio of $\mathrm{NO}$ to $\mathrm{NO}_{2}$ (i.e. $R_{\mathrm{NO} / \mathrm{NO}_{2}}=100: 10$ ), the impacts of four $\mathrm{O}_{3}$ background concentrations(i.e. $\left[\mathrm{O}_{3}\right]=1,20,40$ and 100ppbv) on reactive pollutant dispersion are examined.

It is apparent that the formation of $\mathrm{NO}$ by photolyzing $\mathrm{NO}_{2}$ is slightly dominant in photochemistry when $\left[\mathrm{O}_{3}\right]$ is $1 \mathrm{ppbv}$. In contrast to the reference values $(0.853$ and $0.230 \mathrm{ppm}$ in Table 4, row 3), $\left\langle P \_i F\right\rangle_{\mathrm{W}}$ of $\mathrm{NO}_{2}$ at the leeward and windward walls 
525

526

527

528

529

530

531

532

533

534

535

536

537

538

539

540

541

542

543

544

545

546

slightly decrease(i.e. 0.816 and $0.211 \mathrm{ppm}$ in Table 4 , row 5) while $\left\langle P \_i F\right\rangle_{\mathrm{W}}$ of NO increase a little(i.e. 0.858 and $0.233 \mathrm{ppm}$ ). Besides, such phenomenon is distinctly observed in $\left\langle P \_i F\right\rangle_{\mathrm{B}}$ curves(Fig. 13) between the reference case and Case $\mathrm{R}$ [S10,100:10,1], i.e. $0.207-0.030 \mathrm{ppm}$ against $0.187-0.020 \mathrm{ppm}$ for $\mathrm{NO}_{2}$ (Fig. 13a) and 0.207-0.030ppm against 0.209-0.031ppm for NO(Fig. 13b).

However, if $\left[\mathrm{O}_{3}\right]$ rises from $20 \mathrm{ppbv}$ to 40 and 100ppbv, more $\mathrm{NO}$ is oxidized by $\mathrm{O}_{3}$ to generate $\mathrm{NO}_{2}$. Based on the reference values $(0.853$ and $0.230 \mathrm{ppm}$ in Table 4 , row 3), $\left\langle P \_i F\right\rangle_{\mathrm{W}}$ of $\mathrm{NO}_{2}$ become about 1.9-5.2 times greater $(1.643,2.454$ and 4.442ppm in Table 4, column 2) at leeward wall and 2.6-6.7 times larger (0.610, 0.944 and $1.534 \mathrm{ppm}$ in Table 4, column 4) at windward wall; while $\left\langle P \_i F\right\rangle_{\mathrm{W}}$ of NO reduces approximately $9 \%-42 \%(0.775,0.694$ and $0.495 p p m$ in Table 4 , column 3$)$ at leeward wall and 16\%-57\% (0.193, 0.159 and 0.100ppm in Table 4, column 5) at windward wall. Furthermore, Fig. 13 and Table 5 display the corresponding $\left\langle P \_i F\right\rangle_{\text {B }}$ curves, $\left\langle P_{-} i F_{t}\right\rangle_{\mathrm{B}}$ values and decay factors $b$ under different $\left[\mathrm{O}_{3}\right]$. As depicted in Fig. 13, compared with Case $\mathrm{R}[\mathrm{S} 10,100: 10,20]$, Case $\mathrm{R}[\mathrm{S} 10,100: 10,100]$ and $\mathrm{R}$ [S10,100:10,40] obviously attain much larger $\left\langle P \_i F\right\rangle_{\mathrm{B}}$ of $\mathrm{NO}_{2}(1.573-0.275$ and 0.952-0.218ppm in Fig. 13a) and smaller $\left\langle P \_i F\right\rangle_{\mathrm{B}}$ of NO (0.071-0.005 and $0.133-0.011 \mathrm{ppm}$ in Fig. 13b). Additionally, both decay factors of $\mathrm{NO}_{2}$ and $\mathrm{NO}$ are smaller $\left(b=6.02\right.$ and 2.33 for $\left[\mathrm{O}_{3}\right]=40 \mathrm{ppbv}, b=4.74$ and 1.87 for $\left[\mathrm{O}_{3}\right]=100 \mathrm{ppbv}$ in Table 5, row 6-7) than those in Case R[S10,100:10,20] ( $b=6.84$ and 2.91 in Table 5, row 4 ), which implies higher $\left[\mathrm{O}_{3}\right]$ induces the quicker decay of $\left\langle P_{-} i F\right\rangle_{\mathrm{B}}$ curves for $\mathrm{NO}_{\mathrm{x}}$ with $\mathrm{S} 10$ sources toward downstream building units. By concentrating on 
547

548

549

550

551

552

553

554

555

556

557

558

559

560

561

562

563

564

565

566

567

$\left\langle P \_i F_{t}\right\rangle_{\mathrm{B}}, \mathrm{NO}_{2}$ exposure in R-type cases surpass the reference case nearly $2.9,4.6$ and 7.6 times for $\left[\mathrm{O}_{3}\right]=20,40$ and 100ppbv, respectively(Table 5, column 2). Correspondingly, $\left\langle P \_i F_{t}\right\rangle_{\mathrm{B}}$ of $\mathrm{NO}$ in these $\left[\mathrm{O}_{3}\right]$ cases are about $19 \%, 36 \%$ and $66 \%$ smaller than the reference values, respectively(Table 5, column 4). It clearly indicates that increasing $\left[\mathrm{O}_{3}\right]$ would aggravate $\mathrm{NO}_{2}$ exposure within urban clusters but is conductive to the mitigation of $\mathrm{NO}$ exposure.

\subsubsection{Effects of emission ratio of $\mathrm{NO}$ to $\mathrm{NO}_{2}\left(\mathrm{R}_{\mathrm{NO} / \mathrm{NO}_{2}}\right)$}

The effects of source emission ratios $\left(R_{\mathrm{NO} / \mathrm{NO}_{2}}=100: 10,50: 10\right.$ and 100:20) on reactive pollutant dispersion are investigated with the same $\left[\mathrm{O}_{3}\right]$ of $20 \mathrm{ppbv}$.

It is shown that decreasing $\mathrm{NO}$ or increasing $\mathrm{NO}_{2}$ emissions based on the reference case can mildly change the fraction of $\mathrm{NO}$ converting into $\mathrm{NO}_{2}$. For example, reducing $R_{\mathrm{NO}_{\mathrm{NO}}}$ from $100: 10$ to $50: 10$ and $100: 20,\left\langle P \_i F\right\rangle_{\mathrm{W}}$ of NO varies from 0.775 to 0.744 and $0.784 \mathrm{ppm}$ at the leeward wall(Table 4, column 3), and from 0.193 to 0.186 and $0.197 \mathrm{ppm}$ at windward wall(Table 4, column 5). Furthermore, $\left\langle P \_i F\right\rangle_{\mathrm{w}}$ of $\mathrm{NO}_{2}$ drops from 1.643 to 1.406 and $1.205 \mathrm{ppm}$ at the leeward wall(Table 4, column 1), and from 0.610 to 0.453 and $0.400 \mathrm{ppm}$ at windward wall(Table 4 , column 4). In addition, Fig. 14 presents $\left\langle P \_i F\right\rangle_{\mathrm{B}}$ curves of $\mathrm{NO}_{2}$ and $\mathrm{NO}$ in P-type and R-type cases with three $\mathrm{NO}-\mathrm{NO}_{2}$ emission ratios. Obviously, photochemical reactions in these R-type cases are still dominated by the depletion of $\mathrm{O}_{3}$ with $\mathrm{NO}$ to produce $\mathrm{NO}_{2}$ 
$569[\mathrm{~S} 10,100: 20,20]$ obtain smaller $\left\langle P_{-} i F\right\rangle_{\mathrm{B}}$ and decay factor of $\mathrm{NO}_{2}$ (i.e. $0.446-0.091$

570 ppm, $b=5.41$ and 0.384-0.088ppm, $b=6.00$ ) than those in Case R[S10,100:10,20] (i.e.

$5710.605-0.160 \mathrm{ppm}, b=6.84)$. In contrast to Case R[S10,100:10,20], $\left\langle P_{-} i F_{t}\right\rangle_{\mathrm{B}}$ of NO in

572 Case R[S10,50:10,20] and R[S10,100:20,20] reduce nearly 26\% and 37\%. However,

$573\left\langle P \_i F\right\rangle_{\mathrm{B}}$ curves and decay factors $b$ of NO are quite close between three R-type cases,

574 i.e. $0.172-0.018,0.168-0.018$ and $0.160-0.017 \mathrm{ppm} ; b=3.05,2.91$ and 3.11(Fig. 14b

575 and Table 5). It is confirmed that the decrement of $R_{\mathrm{NO}_{\mathrm{NO}}}$ (from 10 to 5) can partly

576 offset $\mathrm{NO}_{2}$ exposure but have much less impacts on $\mathrm{NO}$ exposure.

577

Overall, the $\mathrm{NO}_{\mathrm{x}}-\mathrm{O}_{3}$ photochemical processes dependent on the initial proportion of reactive pollutants are toward satisfying the photostationary state relationship (i.e. $\left.k_{1}[\mathrm{NO}]\left[\mathrm{O}_{3}\right]=J_{\mathrm{NO}_{2}}\left[\mathrm{NO}_{2}\right]\right)$.

\subsection{Limitations and future work}

Since the 3D urban district models, photochemical reactions and meteorological conditions adopted in this study are fairly simplified, the present exposure results may change if more realistic factors are taken into account, such as more realistic urban configurations(e.g. with variations of building height and street width), more complicated chemical mechanisms(e.g. VOCs- $\left.\mathrm{NO}_{\mathrm{x}}-\mathrm{O}_{3}\right)$ and more realistic atmospheric conditions etc. It is worth mentioning that the chemical processes dependent on reaction rates are highly associated with the reactive pollutant 
589

590

591

592

593

594

595

596

597

598

599

600

601

602

603

604

605

606

607

608

609

concentration and ambient air temperature. Moreover, realistic atmospheric conditions include the unsteady temporal and spatial variations of wind speed and direction as well as various atmospheric stabilities and solar radiation conditions. Thus, further unsteady CFD simulations will be performed to examine the integrated impacts of urban turbulence and solar radiation on reactive pollutant dispersion in 3D urban districts.

\section{Conclusions}

Urban residents in near-road buildings commonly suffer from high exposure risk of vehicular pollutants in which $\mathrm{NO}_{\mathrm{x}}\left(\mathrm{NO}\right.$ and $\left.\mathrm{NO}_{2}\right)$ act as primary reactive pollutants. With satisfactory full-scale CFD validation of flow and pollutant dispersion by experimental data, this study first focuses on the impact of turbulent transport combined with $\mathrm{NO}_{\mathrm{x}}-\mathrm{O}_{3}$ photochemical reactions on reactive pollutant dispersion in neighborhood-scale(21-row, $\sim 1 \mathrm{~km}$ ) three-dimensional(3D) medium-dense urban clusters $\left(H / W=1, \lambda_{p}=\lambda_{f}=0.25\right)$. Ground-level emission sources of $\mathrm{NO}$ and $\mathrm{NO}_{2}$ are considered in the presence of background $\mathrm{O}_{3}$. The approaching wind is parallel to the main streets and perpendicular to the secondary streets. As a start, the influences of various source locations and reactant proportions $\left(\mathrm{NO}: \mathrm{NO}_{2}: \mathrm{O}_{3}\right)$ on pollutant dispersion are investigated under neutral meteorological condition. Personal intake fraction $P \_i F$, its spatially-averaged values for a building wall $\left(\left\langle P \_i F\right\rangle_{\mathrm{W}}\right)$ and the entire building surfaces(i.e. building intake fraction $\left\langle P_{-} i F\right\rangle_{\mathrm{B}}$ ) are adopted to quantify pollutant 
610

611

612

613

614

exposure with and without $\mathrm{NO}-\mathrm{NO}_{2}-\mathrm{O}_{3}$ reactions(i.e. reactive and passive).

Some meaningful findings are summarized as below:

1) There are flow adjustment processes coupling turbulent mixing and chemical reactions through urban building clusters(Street 1 to Street 20 toward downstream).With span-wise sources, the secondary street of Street 10 located in the fully-developed region(i.e. S10 case) experiences weaker wind and subsequently greater $\left\langle P_{-} i F\right\rangle_{\mathrm{B}}$ than the secondary Street 3 located in the upstream flow-adjustment region (i.e. S3 case). Consequently, in contrast to S3 case, photostationary state defect $\left(d_{p s}\right)$ is smaller in S10 case since reactive pollutants have more time to mix and react in Street 10.

2) With source emission ratios of $\mathrm{NO}$ to $\mathrm{NO}_{2}$ of $10\left(R_{\mathrm{NO} / \mathrm{NO} 2}=100: 10\right)$ and background $\mathrm{O}_{3}$ concentration of $20 \mathrm{ppbv}\left(\left[\mathrm{O}_{3}\right]=20 \mathrm{ppbv}\right), \mathrm{NO}-\mathrm{NO}_{2}-\mathrm{O}_{3}$ photochemistry leads to production of $\mathrm{NO}_{2}$ and depletion of $\mathrm{O}_{3}$ and $\mathrm{NO}$, inducing a significant increase in $\mathrm{NO}_{2}$ exposure and a slight decrease in $\mathrm{NO}$ exposure when compared to corresponding passive dispersion which only considers the sole role of turbulent transport. With span-wise pollutant sources, 3D downward helical flows transport more $\mathrm{NO}_{\mathrm{x}}$ to the leeward side, inducing much greater leeward-side $\left\langle P \_i F\right\rangle_{\mathrm{W}}$ than the windward-side. Moreover, by defining exponential decay function expressed in $\left\langle P_{-} i F_{n}\right\rangle_{\mathrm{B}}=a \times\left\langle P_{-} i F_{t}\right\rangle_{\mathrm{B}} \times e^{(t-n) / b}$, it is found that $\left\langle P_{-} i F\right\rangle_{\mathrm{B}}$ descends exponentially from target building $\left(\left\langle P \_i F_{t}\right\rangle_{\mathrm{B}}=0.135 \mathrm{ppm}\right.$ or $0.207 \mathrm{ppm}, t=4$ or 11 for $\mathrm{S} 3$ or $\left.\mathrm{S} 10\right)$ to downstream buildings ( $n=t$ to 21$)$. Especially, $\left\langle P_{-} i F\right\rangle_{\text {В }}$ curves decline more sharply 
631

632 633

634

635

636

637

638

639

640

641

642

643

644

645

646

647

648

649

650

from Street 10 toward downstream than that from Street 3. However, if stream-wise sources fixed along the main streets, $\left\langle P \_i F\right\rangle_{\mathrm{B}}$ first ascends quickly from building No.1 to 8 , then reaches approximate equilibrium values of $\left\langle P_{-} i F\right\rangle_{\mathrm{B}}=$ 0.046-0.049ppm.

3) Furthermore, the $\mathrm{O}_{3}$ background concentration $\left(\left[\mathrm{O}_{3}\right]\right)$ and source emission ratios of $\mathrm{NO}$ to $\mathrm{NO}_{2}\left(R_{\mathrm{NO} / \mathrm{NO}_{2}}\right)$ are confirmed as key factors on $\mathrm{NO}_{\mathrm{x}}-\mathrm{O}_{3}$ reactive dispersion. The formation of $\mathrm{NO}$ by photolyzing $\mathrm{NO}_{2}$ is slightly dominant in photochemistry when $\left[\mathrm{O}_{3}\right]$ is $1 \mathrm{ppbv}$. However, if $\left[\mathrm{O}_{3}\right]$ rises from $20 \mathrm{ppbv}$ to 40 and 100ppbv, more $\mathrm{NO}$ is oxidized by $\mathrm{O}_{3}$ to generate $\mathrm{NO}_{2}$, which would aggravate $\mathrm{NO}_{2}$ exposure within urban clusters but is conductive to the mitigation of NO exposure. Under $\left[\mathrm{O}_{3}\right]$ of $20 \mathrm{ppbv}$, results show that the decrement of $R_{\mathrm{NO}_{\mathrm{NO}}}$ from 10 to 5 can partly offset $\mathrm{NO}_{2}$ exposure but have much less impacts on $\mathrm{NO}$ exposure.

Although further investigations are still required to provide practical guidelines, this paper is one of the first attempts to quantify how reactive pollutant source locations and reactant proportions influence reactive pollutant exposure in $3 \mathrm{D}$ urban districts, which can present meaningful references for urban planning. The effective methodologies are proposed for reactive pollutant exposure assessment in more complicated urban districts with various meteorological conditions and chemical mechanisms. 
652

653

654

655

656

657

658

659

660

661

662

663

664

665

666

667

668

669

670

This study was financially supported by National Key R\&D Program of China [2016YFC0202206, 2016YFC0202205 and 2016YFC0202204], the National Science

Fund for Distinguished Young Scholars (No. 41425020) and National Natural Science Foundation--Outstanding Youth Foundation (No. 41622502), STINT (dnr CH2017-7271) and the National Natural Science Foundation of China (No. 51811530017 and 41875015).

\section{References list}

[1] Fenger, J., 1999. Urban air quality. Atmos. Environ. 33(29): 4877-4900.

[2] Chan, C.K., Yao, X.H., 2008. Air pollution in mega cities in China. Atmos. Environ. 42: 1-42.

[3] Pu, Y.C., Yang, C., 2014. Estimating urban roadside emissions with an atmospheric dispersion model based on in-field measurements. Environ. Pollut. 192: 300-307.

[4] Luo, Z.W., Li, Y.G., Nazaroff, W.W., 2010. Intake fraction of nonreactive motor vehicle exhaust in Hong Kong. Atmos. Environ. 44: 1913-1918.

[5] Chen, C., Zhao, B., Zhou, W.T., Jiang, X.Y., Tan, Z.C., 2012. A methodology for predicting particle penetration factor through cracks of windows and doors for actual engineering application. Build. Environ. 47: 339-348. 
671 [6] Ji, W.J., Zhao, B., 2015. Estimating mortality derived from indoor exposure to 672 particles of outdoor origin. PLOS.ONE.10, 0124238.

673 [7] Hang, J., Luo, Z.W., Wang, X.M., He, L.J., Wang, B.M., Zhu, W., 2017. The influence of street layouts and viaduct settings on daily $\mathrm{CO}$ exposure and intake fraction in idealized urban canyons. Environ. Pollut. 220: 72-86.

[8] Ng, W., Chau, C., 2014. A modeling investigation of the impact of street and building configurations on personal air pollutant exposure in isolated deep urban

[9] He, L.J., Hang, J., Wang X.M., Lin B.R., Li, X.H., Lan, G.D., 2017. Numerical 584-585: 189-206.

683

[10]Scungio, M., Stabile, L., Rizza, V., Pacitto, A., Russi, A., Buonanno, G., 2018. layout on air flow and pollutant dispersion in non-uniform street canyons. Build. Environ. 46: 2657-2665.

[12] Yuan, C., Ng, E., 2012. Building porosity for better urban ventilation in high-density cities - A computational parametric study. Build. Environ.50: 
693

694

695

696

697

698

699

700

701

702

703

704

705

706

707

708

709

710

711

[13]Blocken, B., Vervoort, R., van Hooff, T.A.J., 2016. Reduction of outdoor particulate matter concentrations by local removal in semi-enclosed parking garages: a preliminary case study for Eindhoven city center. J. Wind Eng. Ind. Aerodyn. 159: 80-98.

[14]Santiago, J.L., Borge, R., Martin, F., de la Paz, D., Martilli, A., Lumbreras, J., Sanchez, B., 2017. Evaluation of a CFD-based approach to estimate pollutant distribution within a real urban canopy by means of passive samplers. Sci. Total Environ. 576: 46-58.

[15]Wang, W.W., Xu, Y., Ng, E., Raasch, S., 2018. Evaluation of satellite-derived building height extraction by CFD simulations: A case study of neighborhood-scale ventilation in Hong Kong. Landscape. Urban. Plan. 170: $90-102$.

[16]Oke, T.R., 1988. Street design and urban canopy layer climate. Energ. Buildings. 11: 103-113.

[17] Vardoulakis, S., Fisher, B.E.A., Pericleous, K., Gonzalez-Flesca, N., 2003. Modelling air quality in street canyons: a review. Atmos. Environ. 37: 155-182.

[18]Fernando, H.J.S., Zajic, D., Di Sabatino, S., Dimitrova, R., Hedquist, B., 2010. Flow, turbulence, and pollutant dispersion in urban atmospheres. Phys. Fluids. 22: $1-20$. 
712

713

714

715

716

717

718

719

720

721

722

723

724

725

726

727

728

729

730

731

[19]Britter, R.E., Hanna, S.R., 2003. Flow and dispersion in urban areas. Annu. Rev. Fluid. Mech. 35: 469-496.

[20]Di Sabatino, S., Buccolieri, R., Salizzoni, P., 2013. Recent advancements in numerical modelling of flow and dispersion in urban area: a short review. Int. J. Environ. Pollut. 52: 172-191.

[21]Blocken, B., 2015. Computational fluid dynamics for urban physics: importance, scales, possibilities, limitations and ten tips and tricks towards accurate and reliable simulations. Build. Environ. 91: 219-245.

[22] Srebric, J., Heidarinejad, M., Liu, J.Y., 2015. Building neighborhood emerging properties and their impacts on multi-scale modeling of building energy and airflows. Build. Environ. 91: 246-262.

[23]Meroney, R.N., 2016.Ten questions concerning hybrid computational/physical model simulation of wind flow in the built environment. Build. Environ. 96: $12-21$.

[24]Toparlar, Y., Blocken, B., Maiheu, B., van Heijst, G.J.F., 2017. A review on the CFD analysis of urban microclimate. Renew. Sustain. Energy Rev. 80: 1613-1640.

[25]Zhong, J., Cai, X.M., Bloss, W.J., 2016. Coupling dynamics and chemistry in the air pollution modelling of street canyons: A review. Environ. Pollut. 214: 690-704 
732

733

734

735

736

737

738

739

740

741

742

743

744

745

746

747

748

749

750

751

[26]Zhang Y.W., Gu Z., Chuck W. Y., 2018. Review on numerical simulation of airflow and pollutant dispersion in urban street canyons under natural background wind conditions. Aerosol. Air. Qual. Res. 18: 780-789.

[27]Blocken, B., 2018. LES over RANS in building simulation for outdoor and indoor applications : A foregone conclusion? Build. Simul. 821-870.

[28]Lai, D., Liu, W., Gan, T., Liu, K., Chen, Q., 2019. A review of mitigating strategies to improve the thermal environment and thermal comfort in urban outdoor spaces. Sci. Total Environ. 661: 337-353.

[29]Li, X., Liu, C.H., Leung, D.Y.C., Lam, K.M., 2006. Recent progress in CFD modelling of wind field and pollutant transport in street canyons. Atmos. Environ. 40: $5640-5658$.

[30]Li, X.X., Liu, C.H., Leung, D.Y.C., 2009. Numerical investigation of pollutant transport characteristics inside deep urban street canyons. Atmos. Environ. 43 (15): 2410-2418.

[31]Lin, L., Hang, J., Wang, X.X., Wang, X.M., Fan, S.J., Fan, Q., Liu, Y.H., 2016. Integrated effects of street layouts and wall heating on vehicular pollutant dispersion and their reentry into downstream canyons. Aerosol Air Qual. Res. 16: $3142-3163$

[32]Ding, S., Huang, Y.D., Cui, P.Y., Wu, J., Li, M.Z., Liu, D.T., 2019. Impact of viaduct on flow reversion and pollutant dispersion in 2D urban street canyon with 
different roof shapes -Numerical simulation and wind tunnel experiment. Sci. Total. Environ. 671: 976-991.

[33]Chang, C.H., Meroney, R.N., 2003. Concentration and flow distributions in urban street canyons: wind tunnel and computational data. J. Wind Eng. Ind. Aerodyn. 91: 1141-1154.

[34]Buccolieri, R., Sandberg, M., Di Sabatino, S., 2010. City breathability and its link to pollutant concentration distribution within urban-like geometries. Atmos. Environ. 44: 1894-1903.

[35]Hang, J., Li, Y.G., 2011. Age of air and air exchange efficiency in high-rise urban areas. Atmos. Environ. 45 (31): 5572-5585.

[36] Yuan, C., Ng, E., Norford, L.K., 2014. Improving air quality in high-density cities by understanding the relationship between air pollutant dispersion and urban morphologies. Build. Environ. 71: 245-258.

[37]Ramponi, R., Blocken, B., de Coo, L.B., Janssen, W.D., 2015. CFD simulation of outdoor ventilation of generic urban configurations with different urban densities and equal and unequal street widths. Build. Environ. 92: 152-166.

[38]Chen, L., Hang, J., Sandberg, M., Claesson, L., Di Sabatino, S., Wigo, H., 2017. The impacts of building height variations and building packing densities on flow adjustment and city breathability in idealized urban models. Build. Environ. 118: 344-361. 
772

773

774

775

776

777

778

779

780

781

782

783

784

785

786

787

788

789

790

[39]Hang, J., Li, Y.G., Sandberg, M., Buccolieri, R., Di Sabatino, S., 2012. The influence of building height variability on pollutant dispersion and pedestrian ventilation in idealized high-rise urban areas. Build. Environ. 56: 346-360.

[40]Lin, M., Hang, J., Li, Y., Luo, Z., Sandberg, M., 2014. Quantitative ventilation assessments of idealized urban canopy layers with various urban layouts and the same building packing density. Build. Environ, 79: 152-167.

[41]Sha, C.Y., Wang, X.M.,Lin, Y.Y., Fan, Y.F., Chen, X., Hang, J., 2018. The impact of urban open space and 'lift-up' building design on building intake fraction and daily pollutant exposure in idealized urban models. Sci. Total. Environ. 633: 1314-1328.

[42]Liu, J.L., Niu, J.L., Mak, C.M., Xia, Q., 2017. Detached eddy simulation of pedestrian-level wind and gust around an elevated building. Build. Environ. 125: $168-179$.

[43]Du, Y.X., Mak, C.M., Liu, J.L., Xia, Q., Niu, J.L., Kwok, K.C.S., 2017. Effects of lift-up design on pedestrian level wind comfort in different building configurations under three wind directions. Build. Environ. 117: 84-99.

[44]Zhang, K., Chen, G., Wang, X., Liu, S., Mak, C. M., Fan, Y., Hang, J., 2019. Numerical evaluations of urban design technique to reduce vehicular personal intake fraction in deep street canyons. Sci. Total. Environ. 653: 968-994. 
791

792

793

794

795

796

797

798

799

800

801

802

803

804

805

806

807

808

809

[45]Chew, L.W., Nazarian, N., Norford, L., 2017. Pedestrian-level urban wind flow enhancement with wind catchers. Atmos. 8(9): 159 (DOI: 10.3390/ atmos8090159)

[46]Buccolieri, R., Salim, S.M., Leo, L.S., Di Sabatino, S., Chan, A., Ielpo, P., de Gennaro, G., Gromke, C., 2011. Analysis of local scale tree-atmosphere interaction on pollutant concentration in idealized street canyons and application to a real urban junction. Atmos. Environ. 45: 1702-1713.

[47]Buccolieri, R., Santiago, J.L., Rivas, E., Sanchez, B., 2018. Review on urban tree modelling in CFD simulations: Aerodynamic, deposition and thermal effects. Urban for Urban Gree, 31: 212-220.

[48]Gromke, C., Blocken, B., 2015. Influence of avenue-trees on air quality at the urban neighborhood scale. Part I: quality assurance studies and turbulent Schmidt number analysis for RANS CFD simulations. Environ. Pollut. 196: 214-223.

[49] Yuan, C., Norford, L., Ng, E., 2017. A semi-empirical model for the effect of trees on the urban wind environment. Landscape. Urban. Plan. 168: 84-93.

[50]Xie, X.X., Huang, Z., Wang, J.S., 2006. The impact of urban street layout on local atmospheric environment. Build. Environ. 41: 1352-1363.

[51]Cai, X., 2012. Effects of differential wall heating in street canyons on dispersion and ventilation characteristics of a passive scalar. Atmos. Environ. 51: 268-277. 
810

811

812

813

814

815

816

817

818

819

820

821

822

823

824

825

826

827

828

829

830

[52]Allegrini, J., Dorer, V., Carmeliet, J., 2014. Buoyant flows in street canyons: Validation of CFD simulations with wind tunnel measurements. Build. Environ. 72: $63-74$

[53]Yang, X.Y., Li, Y.G., 2015.The impact of building density and building height heterogeneity on average urban albedo and street surface temperature. Build. Environ. 90: 146-156.

[54]Liu, J., Heidarinejad, M., Gracik, S., Srebric, J., 2015. The impact of exterior surface convective heat transfer coefficients on the building energy consumption in urban neighborhoods with different plan area densities. Energy Build. 86: 449463.

[55]Wang, X.X., Li, Y.G., 2016. Predicting urban heat island circulation using CFD. Build. Environ. 99: 82-97.

[56]Fan, Y.F., Hunt, J.C.R., Li, Y.G., 2017. Buoyancy and turbulence-driven atmospheric circulation over urban areas. J. Environ. Sci. 59: 63-71.

[57]Lin, Y., Chen, G., Chen, T., Luo, Z., Yuan, C., Gao, P., Hang, J., 2019. The influence of advertisement boards, street and source layouts on $\mathrm{CO}$ dispersion and building intake fraction in three-dimensional urban-like models. Build. Environ. 150: 297-321.

[58]Habilomatis, G., Chaloulakou, A., 2015. A CFD modelling study in an urban street canyon for ultrafine particles and population exposure: the intake fraction approach. Sci. Total Environ. 530-531: 227-232. 
831

832

[59]Baker, J., Walker, H.L., Cai, X.M., 2004. A study of the dispersion and transport of reactive pollutants in and above street canyons - a large eddy simulation. Atmos. Environ. 38: 6883-6892.

[60]Baik, J.-J., Kang, Y.-S., Kim, J.-J., 2007. Modeling reactive pollutant dispersion in an urban street canyon. Atmos. Environ. 41: 934-949.

[61]Grawe, D., Cai, X.-M., Harrison, R.M., 2007. Large eddy simulation of shading effects on $\mathrm{NO}_{2}$ and $\mathrm{O}_{3}$ concentrations within an idealised street canyon. Atmos. Environ. 41: 7304-7314.

[62]Kang, Y.-S., Baik, J.J., Kim, J.J., 2008. Further studies of flow and reactive pollutant dispersion in a street canyon with bottom heating. Atmos. Environ. 42: 4964-4975.

[63]Tong, N.Y.O., Leung, D.Y.C., 2012. Effects of building aspect ratio, diurnal heating scenario, and wind speed on reactive pollutant dispersion in urban street canyons. J. Environ. Sci.-China 24: 2091-2103.

[64]Zhong, J., Cai, X.M., Bloss, W.J., 2015. Modelling the dispersion and transport of reactive pollutants in a deep urban street canyon: using large-eddy simulation. Environ. Pollut. 200: 42-52.

[65]Kim, M.J., Park, R.J., Kim, J.J., 2012. Urban air quality modeling with full $\mathrm{O}_{3}-\mathrm{NO}_{\mathrm{x}}-\mathrm{VOC}$ chemistry: implications for $\mathrm{O}_{3}$ and $\mathrm{PM}$ air quality in a street canyon. Atmos. Environ. 47: 330-340. 
851

852

853

854

855

856

857

858

859

860

861

862

863

864

865

866

867

868

869

870

[66]Park, S.J., Kim, J.J., Kim, M.J., Park, R.J., Cheong, H.-B., 2015. Characteristics of flow and reactive pollutant dispersion in urban street canyons. Bound. Layer Meteorol. 108: 20-31.

[67]Garmory, A., Kim, I.S., Britter, R.E., Mastorakos, E., 2009. Simulations of the dispersion of reactive pollutants in a street canyon, considering different chemical mechanisms and micromixing. Atmos. Environ. 43: 4670-4680.

[68]Kwak, K.H., Baik, J.J., 2012. A CFD modeling study of the impacts of $\mathrm{NO}_{\mathrm{x}}$ and VOC emissions on reactive pollutant dispersion in and above a street canyon. Atmos. Environ. 46: 71-80.

[69]Kwak, K.H., Baik, J.J., Lee, K.Y., 2013. Dispersion and photochemical evolution of reactive pollutants in street canyons. Atmos. Environ. 70: 98-107.

[70]Allan, M., Richardson, G.M., Jones-Otazo, H., 2008. Probability density functions describing 24-hour inhalation rates for use in human health risk assessments: an update and comparison. Hum. Ecol. Risk. Assess. 14: 372-391.

[71]Chau, C.K., Tu, E.Y., Chan, D.W.T., Burnett, C.J., 2002. Estimating the total exposure to air pollutants for different population age groups in Hong Kong. Environ. Int. 27: 617-630.

[72]Quang, T.N., He, C., Morawska, L., Knibbs, L.D., Falk, M., 2012. Vertical particle concentration profiles around urban office buildings. Atmos. Chem. Phys. 12: 5017-5030. 
871 [73]Tominaga, Y., Stathopoulos, T., 2013. CFD simulation of near-field pollutant 872 dispersion in the urban environment: A review of current modeling techniques. Atmos. Environ. 79: 716-730.

874 [74]Zhang, Y.W., Gu, Z., Lee, S.C., Fu, T.M., Ho, K.F., 2011. Numerical simulation 875 and in situ investigation of fine particle dispersion in an actual deep street canyon 876 in Hong Kong. Indoor. Built. Environ. 20: 206-216.

877 [75]Salim, S.M., Buccolieri, R., Chan, A., Di Sabatino, S., 2011. Numerical

[76]Ashie, Y., Kono, T., 2011. Urban-scale CFD analysis in support of a climate-sensitive design for the Tokyo Bay area. Int. J. Climatol. 31: 174-188.

882

883 simulation of atmospheric pollutant dispersion in an urban street canyon: comparison between RANS and LES. J. Wind Eng. Ind. Aerodyn. 99: 103-113.

[77]Panagiotou, I., Neophytou, M.K.A., Hamlyn, D., Britter, R.E., 2013. City breathability as quantified by the exchange velocity and its spatial variation in real inhomogeneous urban geometries: An example from central London urban area. Sci. Total Environ. 442: 466-477.

[78]Hang, J., Wang, Q., Chen, X.Y., Sandberg, M., Zhu, W., Buccolieri, R., Di Sabatino, S., 2015. City breathability in medium density urban-like geometries evaluated through the pollutant transport rate and the net escape velocity. Build. Environ. 94: 166-182. 
890

891

892

893

894

895

896

897

898

899

900

901

902

903

904

905

906

907

908

909

[79]Hang, J., Xian, Z., Wang, D., Mak, C. M., Wang, B., \& Fan, Y., 2018. The impacts of viaduct settings and street aspect ratios on personal intake fraction in three-dimensional urban-like geometries. Build. Environ. 143: 138-162.

[80]ANSYS Inc, ANSYS FLUENT User's Guide, (Version 15.0).

[81]Seinfeld, J.H., Pandis, S.N., 1998. Atmospheric Chemistry and Physics. Wiley-Interscience, New York.

[82]Lien, F.S., Yee, E., 2004. Numerical modeling of the turbulent flow developing within and over a 3-D building array, part I: A high-resolution Reynolds-averaged Navier-Stokers approach. Bound-lay. Meteorol. 112: 427-466.

[83]Santiago, J.L., Martilli, A., Martin, F., 2007. CFD simulation of airflow over a regular array of cubes. Part I: three dimensional simulation of the flow and validation with wind-tunnel measurements. Bound-lay. Meteorol. 122: 609-634.

[84]Tominaga, Y., Mochida, A., Yoshie, R., Kataoka, H., Nozu, T., Yoshikawa, M., Shirasawa T., 2008. AIJ guidelines for practical applications of CFD to pedestrian wind environment around buildings. J. Wind Eng. Ind. Aerodyn. 96: 1749-1761.

[85]Franke, J., Hellsten, A., Schlünzen, H., Carissimo, B., 2007. Best practice guideline for the CFD simulation of flows in the urban environment, in: COST Action 732. pp. 1-52.

[86]Franke, J., Hellsten, A., Schlunzen, H., Carissimo, B., 2011.The COST732 Best 
Practice Guideline for CFD simulation of flows in the urban environment a summary. Int. J. Environ. Pollut. 44: 419-427.

912

913

914

915

916

917

918

919

920

921

922

923

924

925

926

927

928

929

930

[87]Brown, M.J., Lawson, R.E., DeCroix, D.S., Lee, R. L., 2001. Comparison of centerline velocity measurements obtained around $2 \mathrm{D}$ and $3 \mathrm{D}$ building arrays in a wind tunnel. Report LA-UR-01-4138, Los Alamos National Laboratory, Los Alamos, pp.7.

[88]Blocken, B., Stathopoulos, T., Carmeliet, J., 2007. CFD simulation of the atmospheric boundary layer: wall function problems. Atmos. Environ. 41: 238252.

[89]van Hooff, T., Blocken, B., 2013. CFD evaluation of natural ventilation of indoor environments by the concentration decay method: $\mathrm{CO}_{2}$ gas dispersion from a semienclosed stadium. Build. Environ. 61: 1-17.

[90]Carslaw, D. C., 2005. Evidence of an increasing $\mathrm{NO}_{2} / \mathrm{NO}_{\mathrm{x}}$ emissions ratio from road traffic emissions. Atmos. Environ. 39(26): 4793-4802.

[91]Di Sabatino, S., Buccolieri, R., Olesen, H.R., Ketzel, M., Berkowicz, R., Franke, J., Schatzmann, M., Schlunzen, K.H., Leitl, B., Britter, R., Borrego, C., Costa, A.M., Trini Castelli, A., Reisin, T.G., Hellsten, A., Saloranta, J., Moussiopoulos, N., Barmpas, F., Brzozowski, K., Goricsan, I., Balczo, M., Bartzis, J.G., Efthimiou, G., Santiago, J.L., Martilli, A., Piringer, M., Baumann-Stanzer, K., Hirtl, M., Baklanov, A.A., Nuterman, R.B., Starchenko, A.V., 2011. COST 732 in practice: the MUST model evaluation exercise. Int. J. Env. Poll.44 (1/2/3/4). 
931

932

933

934

935

936

937

938

939

940

941

942

943

944

945

946

947

[92]Chang, C. H., Meroney, R. N., 2001. Numerical and physical modeling of bluff body flow and dispersion in urban street canyons. J. Wind Eng. Ind. Aerodyn. 89 (14-15): 1325-1334.

[93]Irwin, J.S., 1979. A theoretical variation of the wind profile power-law exponent as a function of surface roughness and stability. Atmos. Environ. 13(1):191-194.

\section{Figure list:}

Fig.1 (a) The population census data of Hong Kong [4]; (b) Time activity patterns for each subgroup in four microenvironments [70].

Fig.2 (a) Idealized 3D urban district models $\left(H / W=1, \quad \lambda_{p}=\lambda_{f}=0.25\right)$; (b) Computational domains and boundary conditions for test cases; (c) The overhead and lateral views of mesh distribution.

Fig.3 Model setups of vehicular emission sources: (a) S3, (b) S10 and (c) Sm.

Fig.4 (a-b) The side and top views of measured points and model configurations in wind tunnel experiment [87]; (c) Computational domains and boundary conditions in CFD validation study; (d) The mesh arrangements in grid sensitivity test.

Fig.5 Results of grid independence test: (a) $\bar{u}(z)$, (b) $\bar{w}(z)$ at Point V1; Comparison of vertical profiles between wind tunnel data and CFD results: (c-e) $\bar{u}(z)$ at Points V1, V4 and V6, respectively; (f-g) $\bar{w}(z)$ and $k(z)$ at Point V1. 
951

952

953

954

955

956

957

958

959

960

961

962

963

964

965

966

967

968

969

970

971

Fig.6 (a-b) The lateral and overhead views of experiment settings in concentration measurement [92]; (c) CFD setups in passive dispersion validation; (d-f) Vertical profiles of stream-wise velocity, turbulence kinetic energy and turbulent dissipation rate in domain inlet.

Fig.7 Comparison of $K$ between wind tunnel data and CFD results applying standard $k$ - $\varepsilon$ model: (a) on the leeward and windward walls; (b) on the central line of roof surface.

Fig.8 (a) Velocity distribution in the pedestrian level of $z=1.5 \mathrm{~m}$; (b-c) Velocity magnitude and 2D streamlines for Street 3 (left) and 10 (right) in the plane of $y=30 \mathrm{~m}$ and $z=1.5 \mathrm{~m}$, respectively; (d) 3D streamlines in Street 3 and 10.

Fig.9 $\mathrm{NO}_{2}$ concentration distribution between P-type (left or above) and R-type (right or below) cases: (a-b) in the plane of $y=30 \mathrm{~m}$ with S3 and S10, respectively; (c-d) in the pedestrian level of $z=1.5 \mathrm{~m}$ with $\mathrm{S} 3$ and $\mathrm{S} 10$, respectively; (e) in the pedestrian level of $z=1.5 \mathrm{~m}$ with $\mathrm{Sm}$.

Fig.10 (a-b) Photostationary state defect between S3 (left) and S10 (right) cases in $y=30 \mathrm{~m}$ and $z=1.5 \mathrm{~m}$, respectively.

Fig. $11 \mathrm{NO}_{2}$ concentration between P-type (left or above) and R-type (right or below) cases: (a-b) on the leeward and windward walls with S3 and S10, respectively; (c) on the entire building walls with Sm.

Fig.12 $\left\langle P \_i F\right\rangle_{\mathrm{B}}$ curves of $\mathrm{NO}$ and $\mathrm{NO}_{2}$ in P-type and R-type cases with various source locations: (a) S3, (b) S10 and (c) Sm, respectively. 
972 Fig. $13\left\langle P \_i F\right\rangle_{\mathrm{B}}$ curves of (a) $\mathrm{NO}_{2}$ and (b) $\mathrm{NO}$ in P-type and R-type cases under four $973 \quad \mathrm{O}_{3}$ background concentrations $\left(\left[\mathrm{O}_{3}\right]=1,20,40,100 \mathrm{ppbv}\right)$.

974 Fig. $14\left\langle P \_i F\right\rangle_{\mathrm{B}}$ curves of (a) $\mathrm{NO}_{2}$ and (b) NO in P-type and R-type cases with three 975 kinds of $\mathrm{NO}-\mathrm{NO}_{2}$ emission ratios.

976

977 Table list:

978 Table 1 Time patterns and breathing rates in each subgroup for indoors at home $(j=1)$

979 Table 2 Summary of all test cases

980 Table 3 Comparison between wind tunnel experiment and CFD simulation

981 Table $4\left\langle P \_i F\right\rangle_{\mathrm{W}}$ (unit: ppm) at leeward and windward walls adjoining the target $982 \quad$ street in S3 and S10 cases

983 Table $5\left\langle P \_i F_{t}\right\rangle_{\mathrm{B}}$ values and the exponential factor $b$ in S3 and S10 cases 